\title{
Milli-International Unit per Milliliter per Kilogram per Meter Squared
}

National Cancer Institute

\section{Source}

National Cancer Institute. Milli-International Unit per Milliliter per Kilogram per Meter

Squared. NCI Thesaurus. Code C119396.

A unit of concentration (biologic activity) equal to one milli-international unit per milliliter, divided by kilograms per meter squared. 